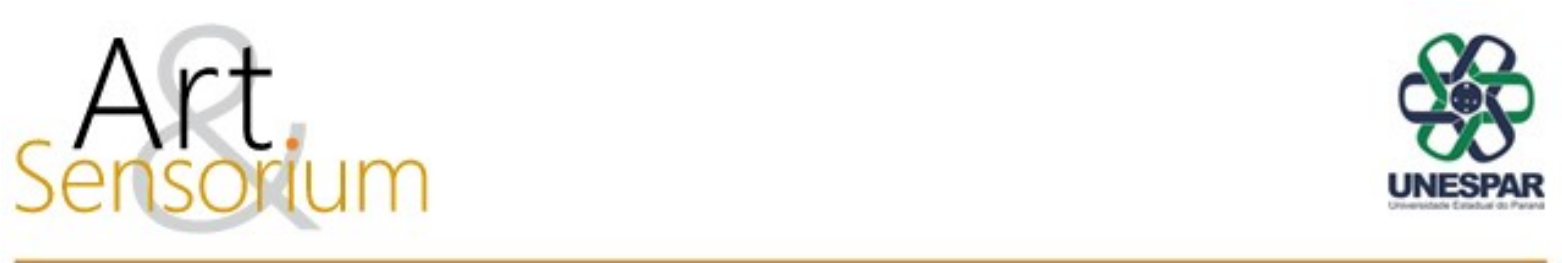

\title{
DO FÍSICO AO FISIOLÓGICO: UM ESTUDO FENOMENOLÓGICO DA COR NAS ARTES
}

https://doi.org/10.33871/23580437.2021.8.1.243-254

Tiago Mendes Alvarez ${ }^{1}$

\begin{abstract}
RESUMO: Ao analisar o fenômeno cromático nas artes, deve-se levar em conta não só os aspectos físicos relacionados ao uso da cor, mas agrupar à percepção, os aspectos fisiológicos fornecidos pelas cores. Neste artigo, pretende-se utilizar como base o estudo fenomenológico da cor efetuado por Johann Wolfgang Von Goethe, em sua obra "Doutrina das Cores" publicado originalmente em 1810 e as experimentações posteriores de Michael-Eugéne Chevreul, efetuadas a partir da primeira edição do livro "Da Lei do Contraste Simultâneo das Cores", de 1839. Com base no desenvolvimento das teorias fisiológicas, esta análise pretende levantar questionamentos sobre a percepção da cor e sua influência nas artes, como também perceber os elementos que fazem parte de um processo complexo de interpretação e decodificação onde a cor poderá, não apenas comunicar, sinalizar ou informar, mas tornar o observador ativo na leitura cromática de elementos apresentados aos olhos e ao cérebro.
\end{abstract}

PALAVRAS CHAVE: fenomenologia; percepção visual; cor; artes

\section{FROM THE PHYSICAL TO PHYSIOLOGICAL: A PHENOMENOLOGICAL STUDY OF COLOR IN THE ARTS}

ABSTRACT: When we analyze the chromatic phenomenon in the arts, one must take into account not only the physical aspects related to the use of color, but bring with of perception, the physiological aspects to provided by colors. In this article, I will intend to use as a basis the phenomenological study of color carried out by Johann Wolfgang Von Goethe, in his work "Theory of Colours" originally published in 1810 and the subsequent experiments by Michael-Eugéne Chevreul, from the first edition of the book "The Laws of Contrast of Colour" published in 1839. Based on the development of physiological theories, this analysis aims to raise questions about the perception of color and its your influence in the arts, as well as to understand the elements that are part of a complex process of interpretation and decodification where the color will may, not only communicate, to aim or inform, but make the observer active in the chromatic reading of elements shown to the eyes and to the brain.

KEYWORDS: phenomenology; visual perception; color; art

\footnotetext{
${ }^{1}$ Doutorando em Comunicação pela Universidade Federal do Paraná - PPGCOM - UFPR, possui graduação em Artes Visuais pela Faculdade de Artes do Paraná (2006); Especialização em Cinema pela Universidade Tuiuti do Paraná (2009); Mestrado em Comunicação e Linguagens na linha de Estudos de Cinema e Audiovisual pela Universidade Tuiuti do Paraná (2012). Atualmente é professor do curso de Bacharelado em Cinema e Audiovisual na Universidade Estadual do Paraná - Campus de Curitiba II - FAP e professor do curso de técnico em Produção de Áudio e Vídeo no Colégio Estadual do Paraná. tiagom.alvarez@gmail.com.br
}

R. Inter. Interdisc. Art\&Sensorium, Curitiba, v.8, n.1, p. 243 - 254 Jan.- Jun. 2021 


\section{DEL FÍSICO A EL FISIOLÓGICO: UN ESTUDIO FENOMENOLÓGICO DEL COLOR EN LAS ARTES}

RESUMEN: Cuando analizamos el fenómeno cromático en las artes, es necesario tener en cuenta no solo los aspectos físicos relacionados con el uso del color, pero traer a la percepción, los aspectos fisiológicos presentados por los colores. En este artículo yo pretendo tomar como base el estudio fenomenológico del color realizado por Johann Wolfgang Von Goethe, en su obra "Teoría de los colores" publicada originalmente en 1810 y los experimentos posteriores de Michael-Eugéne Chevreul, realizados desde la primera edición del libro "De la ley del Contraste Simultáneo de Colores", publicado en 1839. A partir del desarrollo de teorías fisiológicas, esta análisis tiene como objetivo plantear interrogaciones sobre la percepción del color y su influencia en las artes, así como comprender los elementos que forman parte de un complejo proceso de interpretación y decodificación donde el color no solo puede comunicar, señalar o informar, pero hacer que el observador sea activo en la lectura cromática de los elementos presentados a los ojos y a el cerebro.

PALABRAS CLAVES: fenomenología; percepción visual; color; arte

\section{Uma visão subjetiva das cores}

O estudo da ciência das cores está presente na filosofia e nas artes desde seus primórdios. Segundo Israel Pedrosa, há indícios que desde a antiguidade os fenômenos cromáticos "vêm sendo estudados por filósofos e artistas" (PEDROSA, 2014, p.25). Para John Gage, tanto na Idade Média como na Grécia Antiga já havia uma preocupação não somente com a produção artística, mas também com a busca por teorias das cores na aplicação de obras e adereços daquele período. Segundo Gage (2001, p.11), as teorias gregas de cor consideravam, num primeiro momento, a linguagem das cores somente a partir das características de tonalidade e saturação. $\mathrm{O}$ valor cromático e os graus de iluminação de uma determinada tonalidade foram indagações posteriores, conceitos que se enraizaram de forma parcial na teoria grega das cores. Hoje, sabe-se que o fenômeno cromático pode ser interpretado de forma polivalente, considerando variáveis da percepção, abrangendo, portanto, a compreensão da cor na sua totalidade.

A cor vem sendo pautada por muitos anos como objeto de estudo, por meio de experimentações e pesquisas, revelando assim uma série de estudiosos, teóricos e cientistas. Desta forma, a cor vem sendo condicionada à uma historicização que aparece de forma mais contundente na Renascença, onde muitos artistas buscavam questões teóricas na compreensão das cores e suas possíveis dimensões de entendimento. Segundo Pedrosa (2014), ainda no século XV, o arquiteto, pintor e matemático Leo Battista Alberti (1404-1472), um dos primeiros teóricos das artes do Renascimento, antecipa a física moderna a partir da síntese cromática, estabelecendo o vermelho, verde e azul como cores fundamentais que dariam origem a todas as outras cores do espectro. $\mathrm{Na}$ mesma medida, Leonardo da Vinci (1452-1519) demonstra experimentalmente pela primeira vez, a decomposição da luz branca, contribuindo para a avanços científicos sobre os estudos da cor e registrando esses experimentos no chamado Trattato della Pittura. Da Vinci aconselhava outros pintores e defendia sempre a pesquisa e a experimentação, tendo o olho como um objeto de estudo. Segundo Pedrosa (2014, p. 67), para Da Vinci, "a elevada percepção visual que constitui o ato principal da pintura".

Os estudos físicos da cor terão grande progresso a partir de definições matemáticas dos fenômenos cromáticos por volta do século XVII, com a óptica mecanicista de Isaac Newton (1642-1727). A visão de Newton estava calcada na estruturação física das cores, na compreensão do espectro cromático por meio da decomposição da luz. Com sua obra Óptica de 1704, o matemático e astrônomo inglês demonstra êxito a partir de uma experimentação similar à câmara escura ${ }^{2}$. Neste

\footnotetext{
${ }^{2}$ Segundo Laurent Mannoni (2003, p.31-32) também chamada de câmera obscura, em latim, foi um experimento onde se fazia um pequeno orifício no interior de uma sala e onde a luz refletida projeta-se para dentro do espaço, formando a

R. Inter. Interdisc. Art\&Sensorium, Curitiba, v.8, n.1, p. 243 - 254 Jan.- Jun. 2021 
experimento, num espaço totalmente escuro, um feixe de luz entra por um pequeno orifício e, com a utilização de um prisma, a luz se decompõe resultando em sete radiações monocromáticas distintas.

Ao contrário das experiências de Newton, o alemão Johann Wolfgang Von Goethe (1749-1832) irá explorar outras formas de estudo além da física, compreendendo a cor como fenômeno perceptivo. Esta pesquisa se tornará primordial nos estudos de percepção a partir da obra Doutrina das Cores, livro originalmente escrito em 1810, em que o autor ressalta a importância da questão fenomenológica ${ }^{3}$ a partir da experiência fisiológica da cor. Neste sentido, Goethe destaca o olho como elemento significativo para a compreensão das cores e destaca como a relação "luz-olho" tem papel fundamental na mediação dos fenômenos ligados à cromaticidade, dissolvendo, portanto, a perspectiva singular apresentada por Newton. Para Goethe:

\begin{abstract}
Ninguém pode negar a afinidade imediata do olho com a luz, embora seja bem mais difícil pensá-los simultaneamente como uma coisa só. Todavia isso se torna mais evidente quando se diz que uma luz latente vive no olho, podendo ser estimulada ao menor efeito interno ou externo. Na escuridão podemos evocar, com esforço da imaginação, as mais claras imagens. No sonho, os objetos aparecem como em pleno dia. Durante a vigília o mais leve efeito luminoso externo é notado. Quando o órgão sofre um choque mecânico, luz e cores emergem. [...] a cor é um fenômeno elementar da natureza para o sentido da visão, que, como todos os demais, se manifesta ao se dividir e opor, se misturar e fundir, se intensificar e neutralizar, ser compartilhado e repartido, podendo ser mais bem intuído e concebido nessas formas gerais da natureza. (GOETHE, 1993, p.45-46)
\end{abstract}

De certa maneira, Goethe estabelece uma outra visão sobre o aspecto da cor a partir do que pode-se chamar de uma visão subjetiva do objeto. Para o autor Jonathan Crary (2012), Goethe deixa de lado a câmara escura para dar vez ao olho e as sensações possíveis do observador. Segundo Crary, "a experiência óptica que Goethe descreve, apresenta uma ideia de visão que o modelo clássico era incapaz de abarcar" (CRARY, 2012, p.72). A partir das concepções de Goethe, Crary destaca que as cores pertencem ao próprio observador ativo na experiência óptica da percepção das cores, alterando a visão única da cor fomentada por Newton. Portanto, a participação do corpo humano, do olho como ferramenta de visualização, cria uma ruptura e desarticula a passividade, convertendo o observador no "produtor ativo da experiência óptica" (CRARY, 2012, p.72).

A grande descoberta de Goethe perpassa pelo fenômeno de permanência da projeção da cor na retina após o olho manter-se acionado durante um determinado tempo diante de uma cor qualquer. As experiências iniciais de Goethe abarcam as interações do cinza, preto e branco (consideradas cor neste contexto), a partir do simples exemplo da persistência da imagem na retina. Para explicar de maneira mais precisa, o autor Jacques Aumont (2002, p.34) se refere a chamada persistência retiniana, como "prolongamento da atividade dos receptores algum tempo até o fim do estímulo". Em seu livro A Imagem, Aumont define de "mascaramento visual" como estímulo e faz a relação do olho com o tempo na determinação da percepção.

O mascaramento visual: estímulos luminosos que se sucedem bem próximos um do outro podem interagir, de forma que o segundo perturba a percepção do primeiro: é o que se chama de efeito de máscara. Esse efeito reduz a sensibilidade ao primeiro estímulo: percebe-se menos contraste e a acuidade visual é menor. (AUMONT, 2002, p.36)

imagem do lado oposto à do orifício. Segundo Mannoni, o fenômeno da projecao de raios luminosos é conhecido desde a Antiguidade.

${ }^{3}$ Segundo Angela Ales Belo (2006, p.17-18), a palavra fenomenologia é formada por duas partes, ambas originadas de palavras gregas. "Fenômeno" significa aquilo que se mostra e "logos" pode ser traduzido como "a capacidade de refletir". Para Angela, a fenomenologia pode ser definida como reflexão sobre um fenômeno ou sobre aquilo que se mostra.

R. Inter. Interdisc. Art\&Sensorium, Curitiba, v.8, n.1, p. 243 - 254 Jan.- Jun. 2021 
Com um breve período de observação, o efeito de presença latente poderá gerar uma interação sobrepondo camadas e alterando a pureza das cores. Na imagem a seguir (Figura 1), visualiza-se um exemplo de sensação dada pela interação entre duas cores.
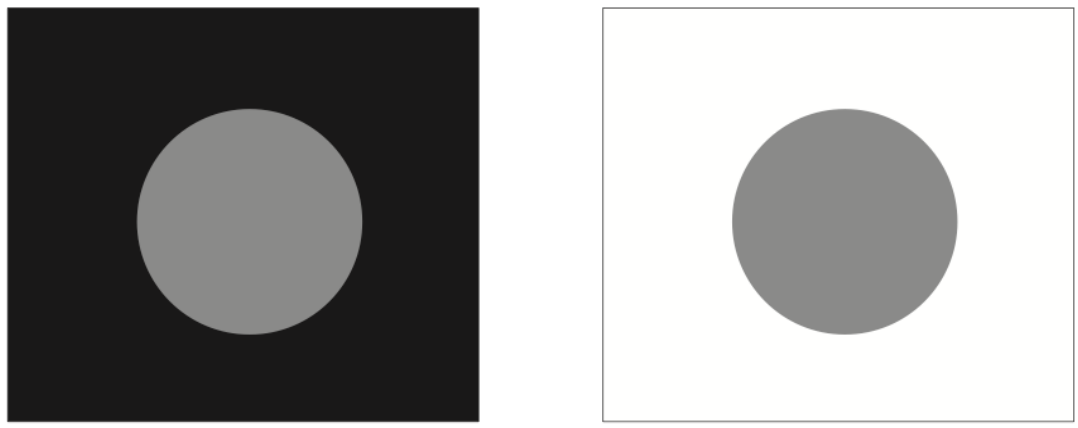

Figura 1. Fonte : Elaborado pelo autor

Ao observar por alguns segundos as duas figuras acima, tem-se a sensação de que o cinza sobre o quadrado preto é mais claro do que o cinza sobre o quadrado branco. Esse fenômeno ocorre pois o olho, ao observar o círculo cinza sobre o quadrado preto, recebe da cor preta o estímulo da sua cor oposta, o branco. A cor branca, ativada pelo olho, "ilumina" o circulo cinza, dando a ele a impressão de maior luminosidade. No quadro à direita, ocorre o inverso. O cinza, por conta da persistência do olho no quadrado branco, recebe a adição da cor preta, tornando-se assim mais escuro. Ocorre que, nas duas situações, o olho é estimulado tentando encontrar seu melhor estado de equilíbrio.

Neste contexto, outro exemplo dado por Goethe se refere à mudança brusca de um lugar completamente escuro a um outro iluminado pelo sol. Quando se está em um lugar sem luminosidade o olho permanece em estado de repouso, a retina não recebe informação luminosa e a íris amplia sua abertura para que se possa enxergar com escassez de luz. Ao se deslocar para um lugar iluminado de forma mais abrupta, o olho não conseguirá se ajustar de um estado de repouso para mais ativo de maneira instantânea. $\mathrm{O}$ exemplo mais comum dessa experiência seria a saída de uma projeção de um filme para um ambiente ensolarado, em que a primeira reação é o ofuscamento dos olhos. Goethe conclui neste exemplo que "quem sai de um lugar pouco iluminado para uma claridade não ofuscante, distingue com mais vivacidade, e melhor, os objetos. Assim um olho em repouso é mais sensível a fenômenos moderados." (GOETHE, 1993, p.55). Portanto, o olho é uma ferramenta perceptiva que depende da atuação fisiológica para compreensão dos objetos e dos espaços. Para Aumont, "o importante é lembrar que os elementos da percepção - luminosidade, bordas, cores - nunca são produzidos de modo isolado, analítico, mas sempre simultâneo, e que a percepção de alguns afeta a percepção de outros." (AUMONT, 2002, p. 30).

À vista disto, para compreender mais afundo a questão da permanência da imagem na retina, Goethe amplia sua pesquisa, associando cada vez mais aspectos da visão ao âmbito biológico do corpo humano.

Uma imagem cinza sobre um fundo preto parece muito mais clara do que a mesma imagem sobre um fundo branco. Comparando os dois casos é difícil se convencer de que as duas imagens tenham a mesma cor. Podemos notar novamente nesse caso a grande sensibilidade da retina e o protesto tácito que cada ser vivo é levado a fazer quando qualquer estado específico lhe é apresentado. É assim que a inspiração pressupõe a expiração e vice-versa, como cada sístole sua diástole. A fórmula eterna da vida também aqui se manifesta. Se oferecemos o escuro ao olho, ele requer o claro e, quando se lhe contrapõe o claro, ele evoca o escuro, mostrando assim sua vitalidade, seu direito de apreender o objeto, produzindo, por si mesmo, algo que é contraposto ao seu objeto. (GOETHE, 1993, p.61) 
Desta forma, após inúmeras investigações, Goethe chegará no entendimento de que a percepção das cores está diretamente relacionada aos fenômenos fisiológicos, físicos e químicos, concordando em parte com a visão newtoniana dos estudos da cor. $\mathrm{O}$ fator fisiológico, será permanentemente $\mathrm{o}$ estado de mudança ou repouso, que dependerá "da capacidade de agir e reagir" (GOETHE, 1993, p. 46). O físico dependerá da luz, seja ela natural ou artificial. Ao atingir um objeto, a luz terá parte do seu espectro refletida e parte absorvida, ou seja, determinadas luzes com determinados comprimentos de onda acarretarão consequentemente em temperaturas de cor diversas. Por fim, cada objeto terá uma composição química, que fará parte da própria matéria. Para a compreensão do modo de visualização de variadas cores, esses três fatores se relacionam diretamente, estruturando de maneira mais coesa o sistema perceptivo.

Em meio aos estudos de Goethe, o pensador e filósofo alemão Arthur Schopenhauer, irá corroborar com as indagações em relação à natureza subjetiva da visão. Apesar de apoiar as ideias de seu conterrâneo, Schopenhauer tinha um pensamento oposto no sentido da não aceitação das categorias físicas e químicas, entendendo que a cor poderia ser analisada tendo como base uma teoria exclusivamente fisiológica. "Para Schopenhauer, a cor era sinônimo de relações e de atividade da retina" (CRARY, 2012, p.77). De fato, no início do século XIX, há uma mudança significativa em relação ao fenômeno da cor e a importância do papel do observador a partir desses conceitos. Segundo Crary:

Inverte-se a prioridade que havia sido outorgada às qualidades primárias de Locke sobre as secundárias. Para Locke, as qualidades secundárias eram as que geravam as várias sensações, e ele insistia em que elas não possuíam nenhuma semelhança com quaisquer objetos reais. Mas para Schopenhauer e para Goethe da doutrina das cores, essas qualidades secundárias constituem nossa primeira e principal imagem de uma realidade externa. (CRARY, 2012, p. 77)

Essas indagações alteram o pensamento da concepção da cor, colocando os objetos reais em segundo plano na dinâmica do modo de visualização. Nessa perspectiva, a partir das indagações de Goethe, é por meio do fenômeno do estímulo da retina e nas mais variadas formas de interação com a capacidade centradas no corpo humano, que a forma de pensar a percepção das cores irá instigar estudos posteriores mais contundentes sobre o fenômeno cromático. São a partir dessas indagações que o cientista francês Michael-Eugéne Chevreul (1786-1889) se tornará um dos maiores influenciadores das artes dos séculos XIX e XX a partir do livro Da Lei do Contraste Simultâneo das Cores.

A partir de observações visuais, Chevreul irá estimular diversas interações a partir de variações, alternando conjuntos de cor, onde a persistência na retina será significativa na mudança cromática em outras cores. A partir de uma camada "impressa" temporariamente no nosso cérebro, a percepção terá como dispositivo o acionamento do olho do observador para as definições de matiz. Novamente, destaca-se o papel ativo do corpo humano na compreensão dos efeitos cromáticos que tornam a leitura da cor uma constante. Com base no mesmo princípio fenomenológico das cores, de permanência da cor na retina, a teoria de Chevreul busca uma perspectiva ainda mais ampla, onde uma cor por influência de outra, sofrerá alterações e poderá transmitir diversas sensações, dependendo da posição em que se encontra. Para Luciana Martha Silveira:

Dentre as suas experiências com as cores, Chevreul definiu como a principal ideia os três tipos: o contraste simultâneo, o contraste sucessivo e o contraste misto, e também apresentou deduções de suas experiências com os contrastes. Baseado nessas experimentações, Chevreul desenvolveu um método para facilitar a percepção, chamado Método de Observação, estabelecido segundo uma tabela de combinações, que descreviam as influências sofridas pelas cores quando colocadas próximas de outras. (MARTHA, 2015, p.32) 
Tomando como base a tabela elaborada por Silveira (2015), a imagem abaixo (Figura 2) revela como a cor sofre modificações e se torna instável diante dos olhos do observador.

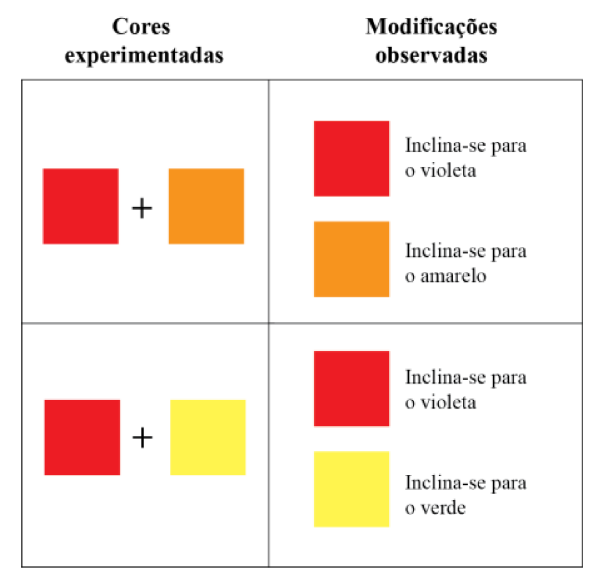

Figura 2. Reelaborado pelo autor. Fonte: Introdução à Teoria das Cores (2015, p. 33)

Retirado do livro Da Lei do Contraste Simultâneo das Cores, a imagem abaixo (Figura 3) exprime de forma clara a influência das cores de forma recíproca.

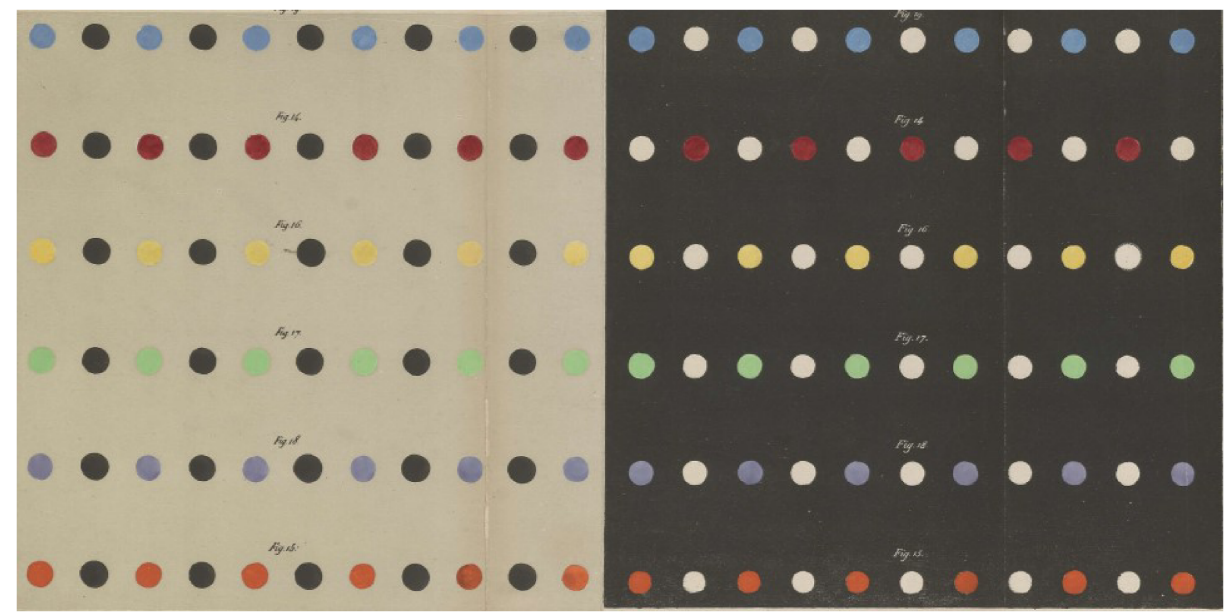

Figura 3. Fonte: https://library.si.edu/exhibition/color-in-a-new-light/using

Neste caso, percebe-se que as cores são mais iluminadas no fundo mais escuro do que as que se localizam à esquerda, no fundo mais claro. Ao observar atentamente, nosso olho observa a grande área escura e reproduz uma camada mais clara às outras cores, dando a sensação visual das cores estarem mais luminosas do que as mesmas cores com o fundo claro. $\mathrm{O}$ olho estabelece relações recíprocas da cor acromática do fundo com as cores monocromáticas da frente, completando o fenômeno de visualização dos elementos do plano. A influência mútua das cores ocorre a partir do momento em que o olho sai do estado repouso e passa mesclar as cores com outra camada cromática latente na retina.

A latência de uma cor, por meio da experiência do observador, irá proporcionar como resultado a chamada cor complementar. A denominação complementar surge a partir da relação de uma cor sensibilizada pelo olho com sua posterior aparição a partir de uma alteração do olhar sobre o objeto. Segundo Aumont, "não apenas os olhos estão quase sempre em movimento, mas a cabeça e o corpo também se movem: a retina está, pois, em movimento incessante em relação ao meio ambiente que ela percebe (AUMONT, 2002, p. 33). O aspecto fisiológico de compreensão das cores também dependerá desses movimentos oculares de mascaramento cromático temporário. Para o autor,

R. Inter. Interdisc. Art\&Sensorium, Curitiba, v.8, n.1, p. 243 - 254 Jan.- Jun. 2021 
existem diversos tipos de movimentos oculares indispensáveis à percepção. Dentre eles, o chamado movimento irregular, estará mais conectado ao fenômeno da visualização das cores. Neste sentido, Aumont destaca que:

Os movimentos irregulares, muito rápidos (cerca de um décimo de segundo), bruscos, voluntários (em uma busca visual, por exemplo, quando se retorna à linha na leitura, ou quando se explora com os olhos uma imagem), ou involuntários (para ir examinar um estímulo detectado na periferia da retina). O tempo de latência (período entre um estímulo e a resposta por ele provocada) é relativamente longo, da ordem de dois décimos de segundo. (AUMONT, 2002, p. 33)

A partir desses movimentos do olho, percebe-se novamente as inúmeras variáveis ao observar um objeto. Tratando-se da cor, de fato, aquilo que se mostra como fenômeno pode ser analisado por diversas vias, tendo o olho como dispositivo importante nas relações perceptivas. Para Crary, "o conhecimento fenomênico começa com a estimulação da retina e se desenvolve segundo a constituição desse órgão.” (CRARY, 2012, p. 77).

\section{Estudos fisiológicos da cor na arte}

As pesquisa desenvolvidas por Goethe e os métodos desenvolvidos por Chevreul, irão influenciar obras de artistas românticos como Eugène Delacroix (1798-1863), como também Joseph Mallord Willian Turner (1775-1851) e, posteriormente, artistas impressionistas e pós-impressionistas. Inúmeras obras de Vincent Van Gogh (1853-90) são expoentes na utilização da cor de maneira estruturada a partir de métodos de observação. Segundo Gage (2016), em meio ao seu processo artístico, Van Gogh se depara com as possíveis transformações da cor e se debruça inteiramente na produção das obras com efeitos variáveis a partir das "Leis das cores". Georges Seurat (1859-91), teve acesso aos estudos de Chevreul, e por meio da técnica do divisionismo (pontilhismo) realizou suas obras a partir de conceitos pertencentes à teria das cores. Seurat se apropriava do que Chevreul chamava de mescla óptica, ou partitiva. Para elaborar tecnicamente seus trabalhos, a sobreposição das cores se dava por contraste sucessivo, ou seja, o espectador observava os pontos de cor na tela e, a partir de uma primeira impressão na retina, sucessivamente as cores latentes se misturavam com as outras, determinado as misturas da pintura.

Desta forma, a participação ativa do corpo envolveria não só o efeito dado pela visão - do contraste sucessivo e do movimento do olho, mas também a posição física de distanciamento do observador. Essa mesma "técnica" de visualização se expande para os impressionistas, onde havia a necessidade de observar a grande maioria das obras a uma distância significativa das telas.

O fascínio pela luz irá alterar a percepção de artistas como Henri Matisse (1869-1954). Supõe-se que a partir de uma sensação de persistência da retina, em que o sol iluminava seu jardim, Matisse, ao olhar para uma tonalidade verde intensa, o fez "ver", posteriormente, uma cor avermelhada nas paredes de seu estúdio acinzentado. A partir dessa experiência da visão, Matisse irá experimentar as cores pensando em harmonias a partir do sistema ocular. Em diversos trabalhos, com base nas observações de Goethe, o artista francês irá compensar um intenso estímulo cromático desenvolvendo uma cor complementar como imagem oposta. $\mathrm{Na}$ imagem abaixo, na pintura $O$ Atelier Vermelho (1911) - Figura 4, Matisse "experimentou uma contraimagem vermelha devido ao efeito que a luz penetrava através das janelas azuis e verdes que havia desenhado" (GAGE, 2001, p.198). 


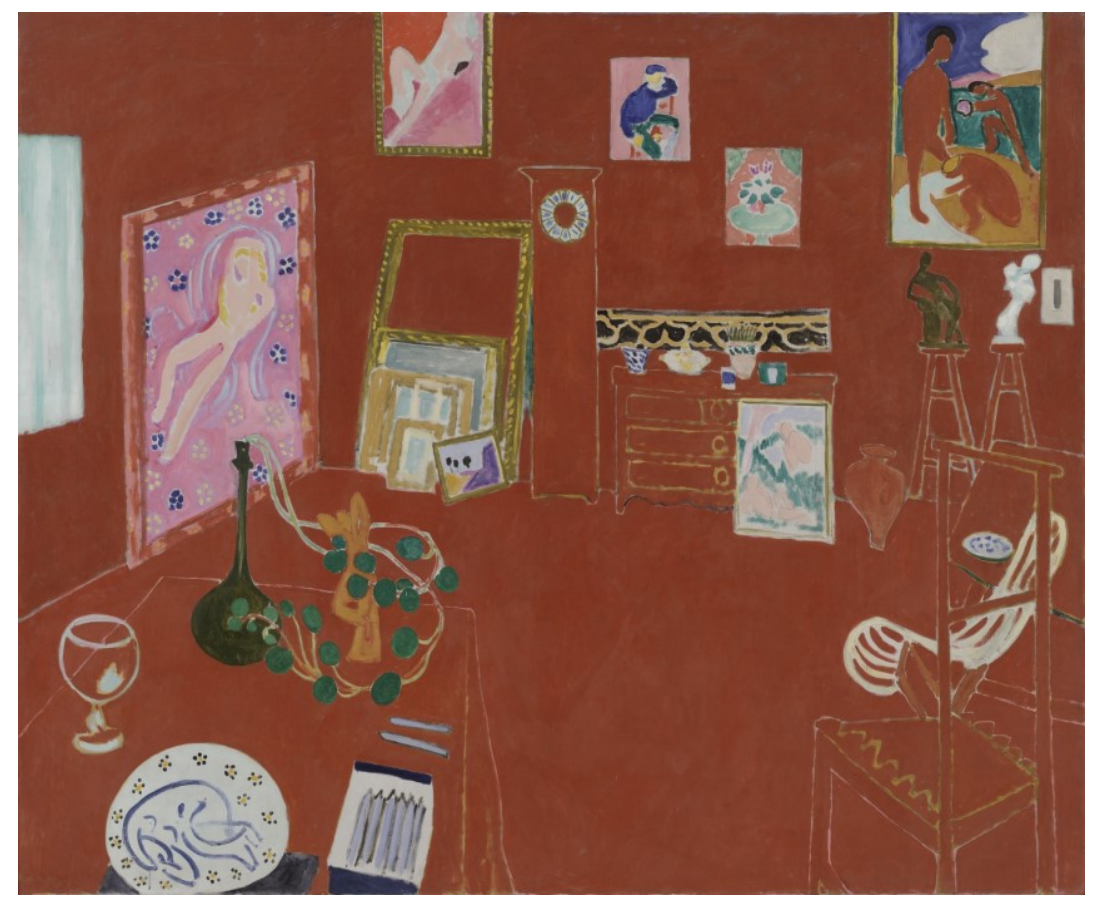

Figura 4. Fonte: https:/www.moma.org/collection/works/78389

Segundo Gage (2001), nem todos os artistas tinham uma preocupação ou atenção aos estudos da cor. Tanto que, o impressionista Oscar-Claude Monet (1840-1926), que se destacou desenvolvendo estudos da luz, no caso da obra A Catedral de Rouen (1890), como o pós-impressionista Paul Cézanne (1839-1906), que trabalhava suas obras a partir dos contrates de cor como tema da pintura, eram pintores que aparentemente não se importavam com estas questões, mas indiretamente executavam seus trabalhos alinhados à teorias fisiológicas da cor. Segundo Gage

Monet não se importava nem um pouco a problemática naturalista de sua própria subjetividade nem o efeito de um escrutínio prolongado do motivo em sua visão e em suas percepções. Esta era a principal preocupação da psicologia fisiológica contemporânea nas tradição de Helmholtz, uma preocupação que já estava presente nos pensamentos científicos de Goethe e que havia sido a ideia dominante na estética positivista francesa dos anos 70 e 80 . Tão pouco isso preocupava Cézanne, mas é justamente em Cézanne onde encontramos a mais completa e surpreendente forma pictórica de atitudes em relação à cor e a percepção habituais na fisiologia e filosofia francesas. Em uma conferência apresentada em 1855, Helmholtz havia afirmado que "nuca percebemos diretamente os objetos do mundo exterior. Pelo contrário, percebemos tão somente os efeitos que estes objetos produzem em nosso sistema nervoso, e cada vez que percebemos algo é como se fosse o primeiro momento de nossa vida". Na década de 1860 desenvolveu o que era chamada uma "Teoria Empírica da Visão" segundo a qual a percepção visual era o resultado de uma apreensão imediata baseada na intuição e nas capacidades inatas, sendo uma espécie de processo de aprendizagem através da experiência. (GAGE, 2001, p. 209-210)

Para Gage (2001) Cézanne começaria a dar mais atenção as teorias ao final de sua vida. Em uma carta que escreveu em 1905 ao seu colega pós-impressionista e escritor Émile Bernard (1868-1941), o artista francês relata a seguinte frase: "estudando óptica, aprendemos a ver" (GAGE, 2001, p.210). Desta forma, percebe-se que em determinado período da história, a pintura e as teorias estiveram imbricadas, corroborando em conclusões aplicadas às artes, e que de uma certa maneira, permanecem nos tempos atuais. Existem registros de que Goethe, ao longo de sua pesquisa das 
cores, esteve auxiliado pelos amigos Johann Heinrich Meyer (1760-1832) e Angelika Kauffmann (1741-1807), artistas que contribuíram junto à ciência a novas formas de elaboração na pintura. Neste contexto, vale ressaltar a fundamentação da óptica de Hermann von Helmholtz (1821-1894) iniciada pelo fisiologista Johannes Müller (1801-1858), que seria dominante na segunda metade do século XIX e que, segundo Crary (2012) "foi uma das maneiras mais influentes de considerar e compreender um observador no século XIX; uma forma de descrever uma "verdade" sobre a visão e a cognição." (CRARY, 2012, p. 91).

\section{Considerações finais}

Ao longo de todo o século XIX, e posteriormente no século XX, com a ascensão da arte moderna, os artistas se apropriaram de conceitos científicos na elaboração de suas obras, dando à cor um protagonismo preponderante. A concepção da interação das cores e o efeito causado no olho se expandiu de forma significativa nas artes plásticas, contribuindo para definições dos contrastes de cores harmoniosas. Artistas contemporâneos, como é o caso de Sanford Wurmfeld (1942-), se apropriaram do conceito das cores por meio da experiência do olho e do observador. Em sua obra mais significativa, o Ciclorama (2000) - Figura 5, Wurmfeld apresenta uma instalação no formato panorâmico em $360^{\circ}$ com inúmeros pequenos quadrados pintados e distribuídos em sequência espectral. Ao adentrar e observar a obra por um determinado tempo, a retina agrupa as cores a partir da mistura óptica que ocorre no olho e no cérebro. A instalação, inspirada nos panoramas circulares dos séculos XIX e XX, permite ao espectador a participação ativa no processo de entendimento da obra, possibilitando que o espectador possa caminhar no espaço, observando o espectro das cores executando um trajeto de formato circular.

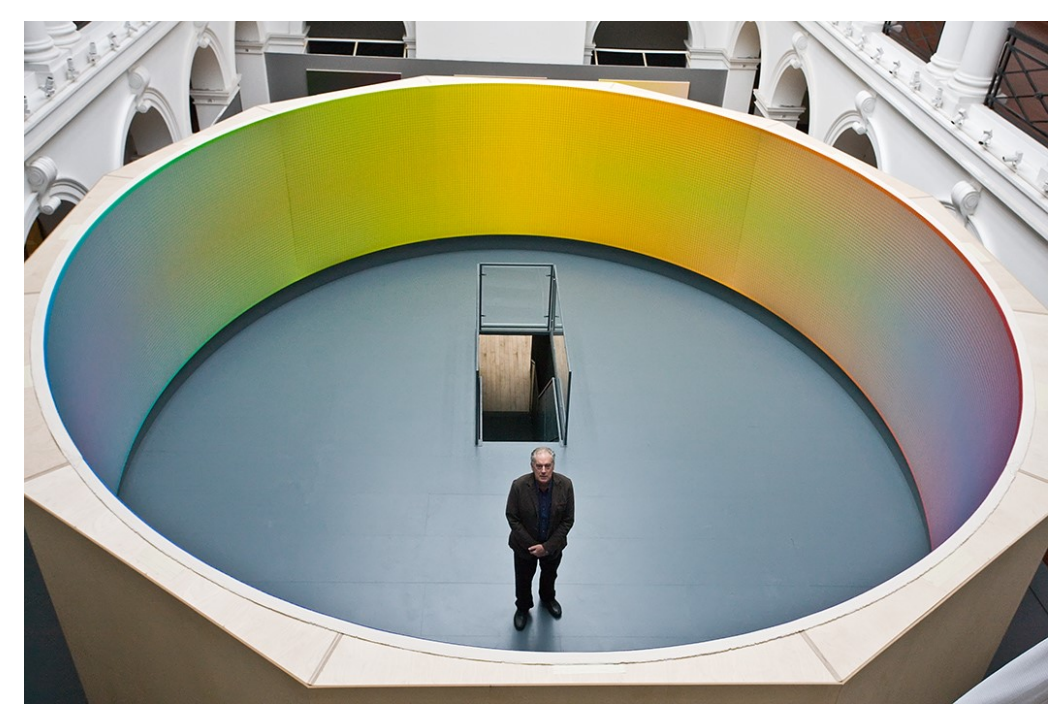

Figura 5. Fonte: http://www.sanfordwurmfeld.com/

O artista plástico norte-americano James Turrel (1943-) tem seu trabalho calcado na cor e na experiência do espectador na transformação da obra. Em uma de suas instalações, com o título Paisagem Noturna (1987) - Figura 6, tem-se um quadro azul montado ao fundo de uma sala com pouca luminosidade. Segundo Gage (2016, p. 42) "a obra de Turrel depende do comportamento do olho humano sob extremos de luz ou sombra." De certa forma, o conceito de fenômeno circula nessas obras que se apropriam de estudos ligados diretamente à fisiologia da cor. 


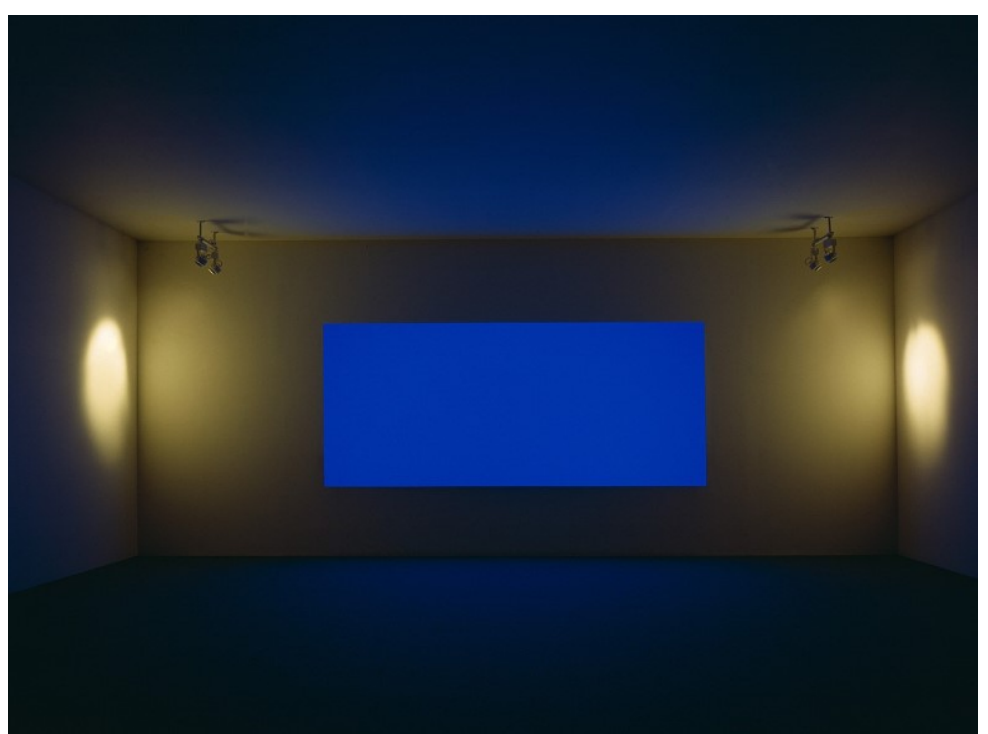

Figura 6. Fonte: https://www.guggenheim.org/artwork/4096

De certa maneira, quando se analisa o uso da cor nas artes, e quando o aspecto cromático está conectado às experimentações fisiológicas, Goethe parece ter papel precursor nas fundamentações que estruturam as obras. Crary (2012) dá o nome de pós-imagem retiniana como "o mais importante fenômeno óptico discutido por Goethe no capítulo sobre as cores fisiológicas em Doutrina das Cores." (CRARY, 2012, p.99). Nas artes, o corpo humano tem se tornado cada vez mais um objeto receptivo no sistema visual. Os conceitos de Chevreaul, Müller, Helmmhotz e tantos outros, vão sendo aos poucos ressignificados na contemporaneidade, tornando o dispositivo interno tão importante quanto o aparato externo no ato perceptivo.

Neste aspecto, quando compreende-se a ideia da visualização a partir da ideia de uma pós-imagem, não há como descartar as mais variadas formas de arte, como também é o caso da imagem em movimento. Sabe-se que o cinema funciona basicamente a partir da latência de uma imagem anterior que é sobreposta por uma imagem posterior, dando assim a sensação do movimento. Esse processo instantâneo de sobreposição de camadas, ficou conhecido pelo fenômeno da persistência retiniana, o que faz com que também se possa refletir sobre a possibilidade de que o fenômeno fisiológico se compõe na presença temporária de fotogramas na retina.

Maurice Merelau-Ponty, irá descrever em seu texto "O Cinema e a Nova Psicologia", que "nossa retina está muito aquém de ser homogêna" (MERELAU-PONTY, 2003, p. 103). Para MerelauPonty, é o conjunto dos elementos que chegam antes de tudo à nossa percepção. Analisando sob o aspecto da linguagem cinematográfica, cada fotograma pode ser considerado uma parte que somado a mais outras partes cria e organiza as imagens no nosso cérebro. Segundo Merelau-Ponty, "a percepção, então, não é uma soma de dados visuais, táteis ou auditivos" (2003, p.105), recebidos pelo corpo de forma segmentada, a percepção é indivisa. É a partir dessa não homogeneidade inicial, que dependerá de aspectos fisiológicos, que olho enxergará verdadeiramente os objetos.

No cinema, o uso da cor cada vez mais vem tomando espaço em obras contemporâneas, principalmente após a evolução tecnológica por meio da colorização digital. $\mathrm{O}$ efeito visual dado pela cromaticidade faz parte de um processo fundamental de elaboração, onde se definem elementos primordiais de maquiagem, figurinos, cenografia, objetos de cena e tipos de iluminação das diversas naturezas de luz e temperaturas de cor. De forma similar ao processo da imagem em movimento da persistência na retina, o processo fisiológico da cor poderá aparecer de forma quase subjetiva, sutilmente percebido durante a sequência de planos cinematográficos. Desta forma, alguns exemplos são necessários para que se possa compreender melhor esse estudo de observação experimental. 


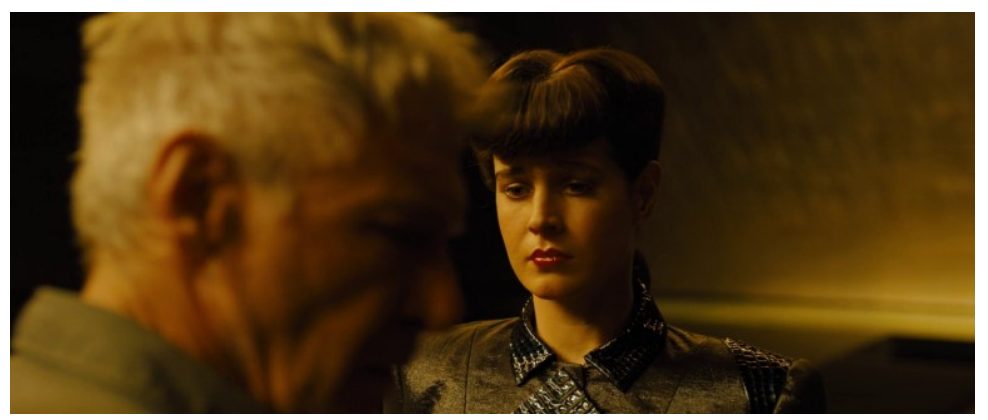

Plano1

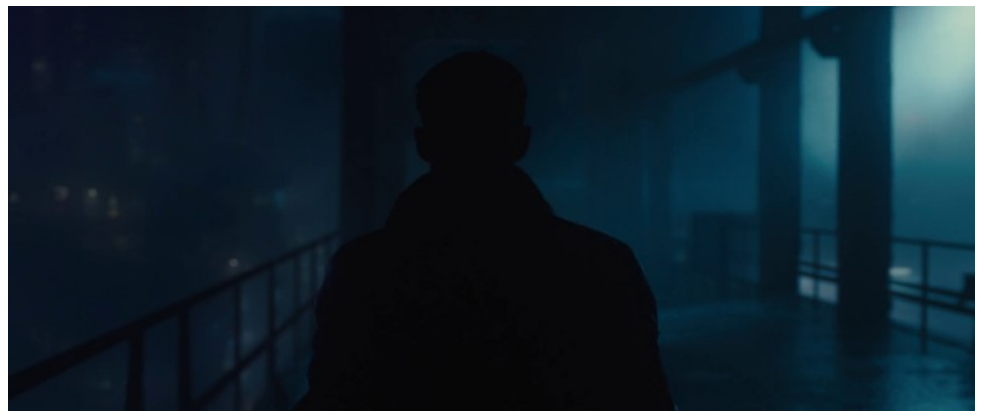

Plano 2

Figura 7. Fonte: Frames retirados do filme Blade Runner 2049 (2017)

Baseado nas teorias de Goethe, a partir do contraste sucessivo, na imagem acima, nota-se no Plano 1 um preenchimento total da cor amarelada. O filme (Figura 7) se dará na sequência do frame amarelo (plano 1) para o frame azulado (plano 2). Ao observar a sequência das imagens - mesmo que em movimento - a passagem do plano 1 para o plano 2, sofre uma pequena alteração de cor dada pela persistência da na retina da cor complementar, gerada pelo estímulo visual dado pela cor amarelada. Em oposição à cor do plano anterior, cria-se uma mancha azul/ciano, como um "máscara retiniana" que cobrirá temporariamente o plano 2. Efetivamente que essa experiência não se dá de forma visível, pois a cor latente (gerada pelo plano 1) se mistura ao plano 2, já azulado. Essa camada azul gerada será temporária e poderá aumentar a saturação do plano 2 por um determinado tempo, até que a retina entre em equilíbrio novamente.

Este fenômeno poderá ser observado em outros filmes que se utilizam principalmente do preenchimento dos planos com filtros de colorização, utilizados na fotografia dos filmes e amplificados na colorização das imagens. Desta forma, outro aspecto a ser estudado, seria a interação das cores em planos com pouca movimentação de câmera e em que a durabilidade se torna mais extensa.

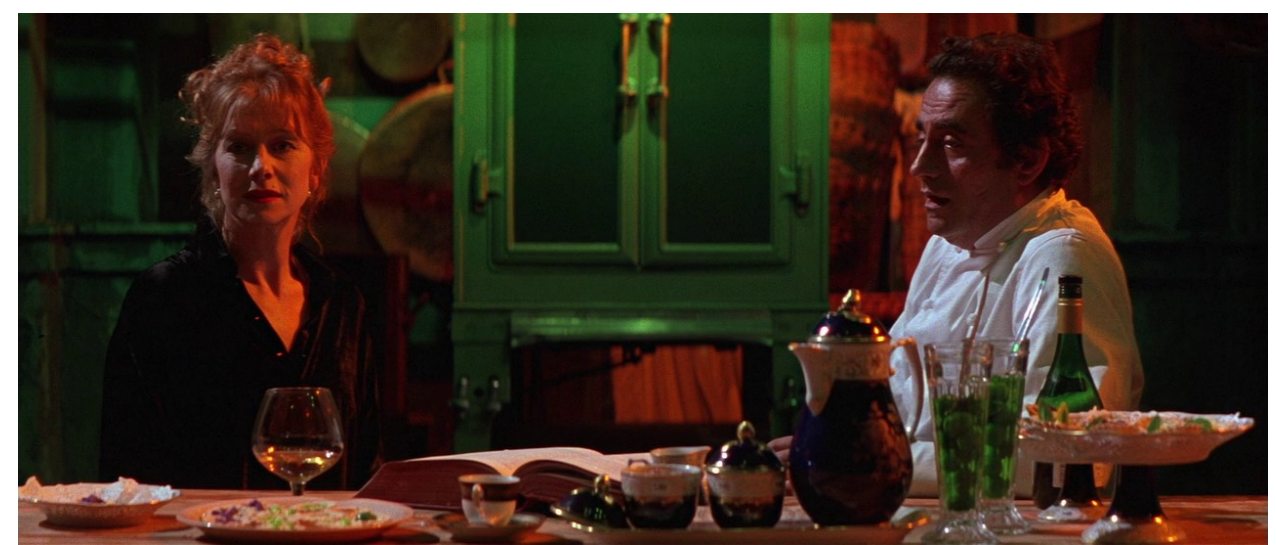

R. Inter. Interdisc. Art\&Sensorium, Curitiba, v.8, n.1, p. 243 - 254 Jan.- Jun. 2021 
Neste caso pode-se aplicar o conceito dado por Chevreul, onde ocorrerá a interação da cores, a partir do contraste simultâneo. O plano do filme acima (Figura 8) permanece neste enquadramento por um longo período. Esse tempo de exposição, faz com que o olho seja estimulado à responder no próprio ato da observação. A tonalidade vermelha do plano irá criar uma cor latente na retina, gerando um tom mais próximo ao ciano. O ciano, por sua vez, irá ajudar na saturação da cor verde presente no enquadramento. $\mathrm{O}$ verde afetará o olho da mesma forma, adicionando um tom próximo ao magenta, enaltecendo a cor vermelha.

Desta forma, os caminhos percorridos pela arte tornam-se cada vez mais transponíveis quando tratase da questão do observador como produtor ativo da experiência óptica, interação que vai além da arte do cinema e seus aspectos cromáticos. Em programas de realidade virtual, a ideia do olho e do corpo passam a ter um papel cada vez mais preponderante nas interações. Neste sentido, assimilar a cor não somente pelo viés físico ou químico torna-se estudo fundamental para a compreensão da percepção visual. Inverter a lógica do modo de visualização clássica da câmara escura, coloca o observador como o próprio objeto que irá remodelar o sentido. O estudo fisiológico da cor nas artes amplia as interpretações e remodela subjetivamente a visualização dos elementos que se apresentam diante de nossos olhos.

\section{REFERÊNCIAS}

ALBERS, J. A interação da cor. São Paulo: Martins Fontes, 2009.

AUMONT, J. A imagem. $7^{\circ}$ ed. São Paulo: Papirus, 2002.

BELLO, A. A. Introdução à fenomenologia. São Paulo: Edusc, 2006.

CRARY, J. Técnicas do observador: visão e modernidade no século XIX. Rio de Janeiro: Contraponto, 2012.

GAGE, J. A cor na arte. São Paulo: Martins Fontes, 2012.

GAGE, J. Color y Cultura: La prática y el significado del color de la Antigüedad a la abstracción. $3^{\circ}$ ed. Madrid: Siruela, 2001.

GOETHE, J. W. V. Doutrina das cores. São Paulo: Nova Alexandria, 1993.

MANNONI, L. A grande arte da luz e da sombra: arqueologia do cinema. São Paulo: SENAC, 2003.

MERLEAU-PONTY, M. O Cinema e a Nova Psicologia. In: XAVIER, Ismail. A experiência do Cinema. Rio de Janeiro: Edições Graal, 1983.

PEDROSA, I. O universo da cor. Rio de Janeiro: Senac, 2004.

SILVEIRA, L. M. Introdução à teoria da cor. $2^{\circ}$ ed. Curitiba: UTFPR, 2015. 